\title{
Interview
}

Leilei Jia*

\section{The Chivalry of a Martial Artist - Interview with Wu Jing}

https://doi.org/10.1515/jcfs-2021-0026

Published online November 10, 2021

Abstract: This dialog was conducted between $\mathrm{Wu}$ Jing, an actor and a film director, and Jia Leilei, a researcher of the Chinese National Academy of Arts, at Director Wu Jing's Studio in Beijing on May 18, 2021. This dialog is about Wu Jing's personal experiences and film concepts including $\mathrm{Wu}$ Jing as a martial artist, $\mathrm{Wu}$ Jing as an actor and a director; his persistence in pursuing authenticity in filmmaking as well as his life philosophy, all highlighting the chivalry of martial artists both in the film world and real life.

Keywords: Wu Jing, filmmaking, martial arts and action films, chivalry, main melody

Translated by: Ruoting Zhang, Communication University of China.

Wu Jing was born in 1974 to a family of martial artists. Influenced by his elders and his surroundings, Wu embarked on his own martial arts journey at the age of six. He joined a martial arts team at 15 and won the jousting and sparring championship at 17. Studying martial arts from a young age both built up Wu's body and courage and also endowed him with typical characteristics of martial artists like integrity and chivalry. Over the course of the 25 years he has worked in the film industry, Wu has created an impressive body of work through his skillful performances in films such as Tai Chi Boxer (Gongfu xiaozi chuangqingguan, Dir. Yuan Heping and Zhang Xinyan, 1996), Kill Zone (Sha po lang, Dir. Ye Weixin, 2005), Twins Mission (Shuangzi shentou, Dir. Jiang Daohai, 2007), Invisible Target (Naner bense, Dir. Chen Musheng, 2007), and Shaolin (Xin shaolinsi, Dir. Chen Musheng, 2011). His career has seen ups and downs, but Wu has never stopped challenging himself. He successfully transitioned from actor to director with the film Legendary

*Corresponding author: Leilei Jia, Chinese National Academy of Arts, Beijing, China, E-mail: jialeilei1008@126.com 
Assassin (Lang Ya, Dir. Li Zhongzhi and Wu Jing, 2008) and the Wolf Warrior film series (Zhan lang in 2015 and Zhan lang 2 in 2017). Wolf Warrior II is the highest grossing Chinese film in history with RMB 5.68 billion in revenues. Growing from his early days as a martial artist to playing heroic figures onscreen and later from an actor to a director, $\mathrm{Wu}$ Jing has demonstrated both his perseverance as a film practitioner and the chivalry of a martial artist.

\section{From a Pupil to a Master}

Jia Leilei (hereinafter referred to as Jia): You were enrolled in Beijing Shichahai Sports School to study martial arts at a very young age. How many years were you there?

Wu Jing (hereinafter referred to as $\mathrm{Wu}$ ): I was enrolled in 1980 and retired in 2000. So I studied there for about 20 years.

Jia: What had you become by the time you finally retired?

Wu: A martial arts coach. After retiring as a student at the school, I stayed there as a coach.

Jia: When did you become interested in martial arts films?

Wu: Everyone dreams about being a martial artist. I wanted to act in martial arts films but was not born at a time when martial arts films were flourishing. In my time, the market had begun to become bored with martial arts films. As technical developments have helped people get more and more proficient in martial arts moves, what is left in films are just moves. They lack "martial artists."

Jia: They lack the spirit of martial artists.

Wu: Exactly. The films become meaningless. No one knows what kinds of core emotions they are intended to express. The times are changing, but filmmakers in China currently have failed to find a new martial arts form that can express our national culture. Each era has previously had its own unique form, but we have not located one for our current era. For example, Jin Yong's novels and the works about "Seven Heroes and Five Gallants" (Qixia wuyi) are both of earlier generations and, respectively, encompass the national cultures of their times.

Jia: It is difficult to identify this type of encompassing form at present.

Wu: It is too difficult. But we have to find one to make our films acceptable to young people. Unfortunately, no one does this now. At present, Chinese films are undergoing marketization and industrialization. Against such a backdrop, it gets much harder to find an encompassing form.

Jia: Do you think existing Chinese films are up to ideal expectations?

Wu: Not yet. I have interacted with a third of the professional staff in the martial arts industry across China and know that not all of them take roles in 
feature films. A large number of them are actually taking roles in online films and TV series. This drains the talent pool of the current film industry. I built my own martial arts center with 30 rooms and a training hall, called "Yingwu Hall." In the training hall, which is more than one thousand square meters, I train my own martial arts team, dividing them into several groups. For instance, if someone is suitable for roles in costume dramas, I will require him to study, plan, and practice according to the topic assigned with the help of synthetic technology. If someone is suitable for roles in modern and military films, he needs to do the same thing. If they are qualified, they can join my team. Let us suppose that you plan to work with me in making a film, then I would design moves for you. If you were to think they're alright, then you could just put them to use. If not, you could find another partner. In any event, we would try to proceed step by step.

Jia: Have you ever thought about introducing such training techniques into colleges?

Wu: The existing teaching of performance in colleges is facing problems. People say that more than two thousand colleges currently offer majors in performance. In the past, martial arts choreographers and performers were trained at specialized martial arts schools. When they were assigned to take roles, they would be told that when $\mathrm{Wu}$ Jing took a role in Kill Zone, he appeared on the screen just two times and spoke only one line, but it was precisely this that made him who he is today. However, the current situation is not like this. Three young people in their twenties can shoot a film that is quite unprofessional by raising just two or three million yuan. It is in response to this that I want to train professional talents and do something more professional as a way to sow seeds of enthusiasm for martial arts films while trying to maintain their original purity.

Jia: I hope someone else would do the same.

Wu: Nowadays, people are living comfortable lives. I can't require them to leave everything behind to be trained as if they were in the army for a dozen months, which is what I did before.

Jia: People seem to be very busy today.

Wu: Yes. Since the situation with the pandemic has eased this year, the number of online films and TV series has been surging, but no one is concentrating on creating good works.

Jia: Is it possible to introduce existing techniques for training professional martial arts staff into the national education system? For example, by setting up majors of martial arts choreography or action film direction in film academies?

Wu: Every action film director hopes to set up a formula for action, but they cannot presently do so.

Jia: Do you mean a procedure for action? 
Wu: No, it is a formula, but not a rigid procedure from A to Z like in the theories of Robert McKee. Up till now, few people have been able to independently establish their own theories. To do so has been our lifelong pursuit. But now I wonder whether time and resources will allow us to accomplish this.

Jia: Martial arts choreographers mainly come from a few groups of people. First, there are those trained at Beijing Shichahai Sports School who have won a number of international awards and not only contributed a lot to the martial arts film and TV industry, but also to the martial arts circle. Second, there are those trained in the theatrical troupes established by Yu Zhanyuan. Last, there are those working on film sets, such as the Tang, Liu, Hong, and Cheng martial arts film teams. The existing film and television colleges train cinematographers, recordists and art directors, why don't they train martial arts choreographers?

Wu: Martial arts choreographers should have a command of basic martial arts as well as experience in shooting films. In this era of marketization and industrialization, once they boast these two skills, they can make money. It is thus unlikely that they will get further education in college. In recent years, I managed to get an MBA degree because I realized that achieving dreams in the market requires a market-oriented thinking ability in addition to fame, a command of martial arts, and experience in shooting films.

Jia: I agree.

\section{Engaging in the Film World and Encountering Good Teachers}

Wu: I, fortunately, had three excellent teachers - Wu Bin, Zhang Xinyan, and Yuan Heping, who all inspired and influenced me greatly. When I took a film role for the first time, the rocker arm with the camera on it had accidentally broken. Seeing this, the director Zhang Xinyan rushed to catch the camera, falling himself in order to protect the camera from being damaged. Several days ago, when I talked with the director Yuan Heping - this time about the film Fu Bei (directed by Er Dongsheng and expected to be released in 2022), which he gave me guidance on-and we recalled how this master took a job back then when the temperature was $41^{\circ} \mathrm{C}$ and he was still completely devoted to his work despite needing a sweat towel. He taught me what responsibility meant, and the need to be responsible for the whole group because what they do makes you who you are. We should be thankful even for those doing odd jobs. And what did the director Zhang want us to do, you know what? He would say "you have finished your job as a hero today. Now, put on the costumes of the extras to play the walk-on parts." 
Jia: Did he tell you to do that when you took the role in the film Tai Chi Boxer?

Wu: Yes, because he wanted me to know that being an extra was very hard. After a day's work as the protagonist, you always have to do some extra jobs, whether that's helping the cameramen hold the tripod or helping people working with props hold a wooden box. This is because they are working with you and you are responsible for making them happy to serve you. However, film units now have lost their awareness of these points. It is reasonable to have someone hold an umbrella for actors when it rains in case their makeup might run, but it is not reasonable to assign several workers to serve an actor at a time. Fortunately, it is great that we have not seen such situations in our film group recently.

Jia: Do you mean the film group involved with The Battle at Lake Changjin (Changiin hu, Dir. Chen Kaige, Xu Ke and Lin Chaoxian, 2021)?

Wu: Yes, all actors in the group have no affectations at all. They only become increasingly professional, diligent, and uncomplaining. This makes the atmosphere in the film group get on the right track. They are willing to bear hardships, grabbing food and eating with dusty hands without any hesitation. This shows their professionalism. I hope that our actors in action films will adhere to the spirit of professionalism and practice these ideas as much as possible.

Jia: You just now named three of your teachers. We already know about the directors Yuan Heping and Zhang Xinyan. Now, let's talk a little about Wu Bing. What kind of person is he?

Wu: He always tells me not to be pretentious, but instead to be modest. I think he is a tough man, though he is not tall. And he is also "cunning." By "cunning," I mean that he is smart and has a certain kind of wisdom. Thus, he can solve various types of problems. If you are not familiar with him, you might think he is a bit of a cold fish, but when you get to know him more, you discover that he is actually an old kid.

Jia: Which genre should martial arts films is categorized as? And what are the rules for the genre?

Wu: I believe you have already summarized a lot of these. I once read an article about the film Fist of Legend (Jingwu yingxiong, Dir. Chen Jiashang, 1994), which analyzes the way the scenes are cut, and the moves are designed. However, it is another thing to actually shoot on the film set. During an onsite shoot, we have to consider where the wire equipment should be placed, which body part the wires should be attached to-on the waist or on the upper part of the body-as well as how to control the wires to make actors do the right moves. If we cannot summarize these points to form a set of theories, we actually fail at our jobs to some degree.

Jia: It seems that nobody summarizes these types of things. They completely rely on figuring them out in practice instead. 
Wu: I am thinking about the questions of whether or not martial arts films can be classified into the category of genre films. If they can, what are the standards and theory of the genre? Every time I have wanted to make a film in recent years, I have had to face the pinnacle represented by the works by Jackie Chan, Jet Li, and Donnie Yen. It would be hard for me to surpass these gems; therefore, all I can do is to chart a new path-specifically, by making military action films. I keep on studying these types of things so that I can have points of reference. However, it is not enough to use the screenwriting theories of books like Story or Save the Cat like a rigid framework. Things might superficially seem like they should be like that, but it will still feel like you are lacking one important element, the "spirit."

Jia: China should have a canonical guide for action movie production.

Wu: You can see that the action moves in foreign films are becoming more and more astonishing. That's because they have developed technologically. Still, even though these films might see technological leaps every 10-15 years, they cannot avoid losing their emotional core at the expense of showing off with set pieces and stunts. Compared to them, we lag behind technologically and industrially to some extent. As a result, we have to explore how to enhance our films through expressing various types of "spirit" and core emotions.

Jia: People have to take a lot of potential risks and even risk their lives to take on roles in martial arts films or to serve as martial arts choreographers. Have you ever encountered risky situations when making films?

Wu: I used to think it was exciting, but who is not afraid of death? I remember one shot where I had to smash into a glass window on the seventh floor at a height of about $75 \mathrm{~m}$ and kept on going back and shooting it again and again. Did I feel scared at that moment? No, instead I felt excited from the very beginning. However, I do also worry about my safety when working in such risky situations for long periods of time, especially since I have started a family. During the shooting of another film, my neck was kicked more than five hundred times in one evening. At the time I thought I should endure it and stick it out, maybe due to my instinct as a martial artist or my sense of dignity. It is only feeling aggrieved. But if you cannot endure it, then you have to leave. You are not irreplaceable. Once, a person came to apologize to me, saying "Wu Jing, I apologize for once claiming to your agent that you would not be a popular star in the future.” I replied, "everyone has low points. It is just that I was unfortunate enough to be seen by you at a low point." I have been grieved, disgraced, and impoverished. But I have always said that it does no good to continue to hold yourself “aloof” when you can't get what you want.

Jia: When you took roles in films in Hong Kong, which Hong Kong director inspired you the most?

Wu: In addition to the three teachers I mentioned before, the director Benny Chan inspired me a lot. Under his direction, I played roles in the film Invisible 
Target, Call of Heroes (Wei cheng, 2016), Shao Lin, and City Under Siege (Quancheng jiebei, 2010). It was he who first recognized my skills and gave me many opportunities and platforms. I feel indebted to him and miss him very much.

Jia: What did you learn from working with these Hong Kong directors?

Wu: I learned fundamental respect for this industry. Each director's professionalism shows respect for the industry. Hong Kong directors always focus on solving problems and they are quite sensitive to these problems. Foreign directors are different from them and tend to follow more rigid filming procedures, but they have learned to be flexible after working with their Chinese counterparts. Since producing a film is not an individual business, both directors and actors have to learn to be flexible. Only by doing so can they prove their professionalism. In fact, after realizing this issue, many directors in China have now learned to be flexible in the face of the restrictions imposed by various regulations.

\section{From Bottoming-Out to a "Wolf Warrior" Rebirth}

Jia: When did you entertain the idea of shifting from being an actor to a director?

Wu: I decided to become a director for two reasons. First, no directors were giving me roles in their films. Second, I did not have enough money to hire a director to make my own films. At the time, no one was willing to spend two to three years producing a low-cost film with me. The production cost of Wolf Warrior was very low, no more than 30 million yuan. That even includes going over budget.

Jia: That means you did not become a director just for the sake of being a director.

Wu: I wanted to be a star, enjoying glories that cannot be achieved as a director. During my time shooting onsite, I had learned how to handle various onsite jobs from the several elders I have already mentioned. I had worked as a cameraman, a dolly grip, a props person, and a script holder. In fact, Hong Kong films influenced us greatly. What they have brought to the world can be found in two areas-namely, action directing and filmmaking. The eye-catching achievements that Chinese mainland films are making nowadays are due to filmmakers who were initially trained in the Hong Kong film industry. They learned a lot and made gradual progress on Hong Kong film sets. As a result, they are even qualified to handle jobs assigned to specific departments when they work on mainland film sets. Besides, because martial arts films are rarely produced in Hong Kong today, the models created by earlier generations are not being inherited by the young generation in Hong Kong, but by mainland Chinese film crews. Of course, there are also a lot of people creating films using the industrial model of Hollywood films. This is incorrect. 
Jia: Wolf Warrior II gained quite good returns, and not just in terms of economic profits. As you said, it represents a kind of genre standard. What makes this film such a big success?

Wu: First, this is a good time. Next, most people did not believe China could produce genre films because all the directors wanted to do the same thing as the art film directors who win awards abroad and thus gain recognition from audiences. This makes winning awards, rather than winning on the commercial market, seems equivalent to gaining recognition. Trace this back to earlier period, many famous directors had to win awards to prove their commercial potential. At present, everyone talks about "the genre of main melody commercial films." This means that we can turn main melody films into commercial films, and that commercial films must stick to mainstream themes. If a commercial film is not in line with mainstream themes, then families will not bring their children to buy tickets. In the past, winning awards meant that a film was a film in line with the right values and a director was a real director. Commercial and action films did not gain recognition on the market. However, Wolf Warrior showed everyone that things could be like this. In fact, as long as a film reflects correct mainstream themes and praises the bright side of life, it can gain recognition. It is the same for martial arts films. The mainstream themes must be right. Based on this, their representational forms can be innovated.

Jia: Some people said that in terms of its overall genre design, Wolf Warriors was, to some extent, similar to American war films. We also refer to such films as heavy industry films, as they include tanks, firearms, and war scenes.

Wu: I had never heard about the concept of heavy industry films before. But actually, all the genre elements, like using tanks, have already existed and are escalating. Within the film's duration of $123 \mathrm{~min}$, we strictly fit the structure to all the key points. However, audiences tend to overlook what we have done, because they do not analyze the film in terms of its construction when watching it. Therefore, they think what we have produced is a film with red themes and are only able to make money through patriotism as a selling point. Could we make the same efforts when producing martial arts and action films? I think we can. Still, in the shadow of the pandemic, people have somewhat changed their mindsets. I wonder whether we could use this time as an opportunity to restore "spirit" to martial arts films. We should take some time to think about this. In most cases, most people don't believe in "chivalry” no matter how you emphasize it in scripts. If you replace this idea with brotherhood or sisterhood, they still will not resonate with it because they are the only child in their family. Besides, females today are pursuing independence. This being the case, it is not proper to define chivalry in outdated ways. If we look at today's heroes who are fighting against the pandemic - doctors, nurses, soldiers, police officers, and all others wearing masks and risking their 
lives-we can find chivalry in them. However, we have to think about what kind of details we should use to demonstrate modern chivalry as well as what kind of antagonists should serve as the foil to modern chivalry. If ideas of chivalry change, will they still be demonstrated through fighting? Our truth, kindness, and beauty are still intertwined with ideas of chivalry. How can we use the martial (wu) as a foil to the chivalrous (xia) in this era of advanced weaponry? This is a profound subject people have not yet researched.

Jia: These are important issues as a matter of fact. Chinese martial arts are deeply rooted in Southern Shaolin, from which many different kinds of martial arts boxing in southern China originate. This history of Southern Shaolin is interesting. Is it possible to create Southern Shaolin-themed works?

Wu: It was possible in the past, but such a genre may not be that popular among today's audiences. A new era requires a new definition of martial arts. How can we achieve a completely new combination of the martial and the chivalrous? How can we integrate modern emotions into the martial arts works? How can we switch between genres? Have positioned our films properly or not? These are the questions we must take into consideration.

Jia: What if your ideas do not gain audience recognition even if they are correct?

Wu: It is unavoidable that a small group of people will not accept these ideas, but the majority of people still accept truth, kindness, and beauty. Otherwise, what do we study for?

Jia: Do you remember the film Painted Skin (Hua pi, Dir. Chen Jiashang, 2008)? This film brought 100 million yuan for Ningxia Film Studio, which prevented this small studio from being closed down. When the director of the studio was asked about their secret of success, he said it was "working day and night, without eating or drinking." Do you have to work that hard on a film set nowadays?

Wu: Everybody is like this. But those who really love films don't mind. Of course, I did meet a young man during the shooting of a film who explicitly said, "it is my turn to go off duty." I responded to him that, "in such a big production team, there are still many things you have to learn. If you want to go down, then go down on your own. It will be your bad luck."

Jia: If you don't love it, then you can't do it.

Wu: Yes, today's life is too comfortable. He was not able to bear hardships, because he had gotten accustomed to a comfortable life. As I have said before, if you canot get what you want, then it is worthless to try to save face.

Jia: Interesting words.

Wu: When I was trained in the army, I soaked myself in sewage for a day to get the genuine experience. Do you want to save face or do you want a genuine 
experience? I choose to know how smelly the sewage and decayed food truly are, so that I know how to respond when playing roles in films.

Jia: Are you capable of producing a film you really like, if conditions allow?

Wu: Yes, I am.

Jia: That's to say you think you can achieve it in terms of both financing and ability to control circumstances.

Wu: It is the resources that matter - the financial and capability resources you have mentioned on the one hand, and my experience on the other hand. I have become older now and will not be as quick-tempered as before. I want to unleash the ideas I have accumulated these years and express them in a mature manner. In this regard, I think I have still only made a little progress.

Jia: I think you can say it is more than just a little progress.

\section{4 “Authenticity" as an Integral Part of Filmmaking}

Jia: How do you think the performances and action in a film develop the narrative?

Wu: In actuality, screenwriters do not design plots without any purposes. When I write something, I especially hope to keep the audiences in the dark about our purposes when designing a detail in a performance. This is where a screenwriter's wisdom lies. And the best way to reveal a screenwriter's purpose is to make it clear via an aspect of everyday life or the trifling matters of everyday life. In other words, we have to show them what hides meaning between the lines.

Jia: The best techniques are those that are invisible.

Wu: Yes. Not only do the screenwriters have to grasp these techniques, but the directors and actors as well. What is the invisible technique? It is "authenticity." We should provide audiences with immersive experiences in authentic things. For example, in a martial arts film, the audiences will not believe that you can really fly. That's just a romantic and unreal scheme for the action. Therefore, we have to restore authenticity via plots. But how do you make action seem genuine? After all, modern martial arts are quite different from traditional ones. When it comes to the authenticity of films, I remember that someone once said that "authenticity is an integral part of filmmaking." It is undeniable that demonstrating authenticity makes films more attractive. But how do you give audiences a sense of authenticity from martial arts and action films? Through a scene where a person is killed with just one sword slash? Or through showy moves? No, not through these, but probably through genuine feelings, simple moves, and flourishes of detail.

Jia: You have both played many characters and created a number of films. Have you ever thought about writing a book on your experiences? 
Wu: I have thought about writing a book, though about raising babies instead of martial arts. I have had a lot of new experiences and feelings since the birth of my first child. These include feelings about my wife's conception, bearing, and raising of my son as well as my ideas of how best to care for my wife as a husband, and for my baby as a father. I wrote down all these feelings, hoping to compile them into a book to help me remember them. But, due to market factors, no one wants to publish it. As a result, it is still unfinished.

Jia: This seems to show how you are pursuing authenticity in life.

Wu: Let's come back to authenticity in films. For example, I remember in Jurassic Park there is a scene where a man vomits as soon as he emerges from a sphere that has been rotating back and forth. This made audiences laugh. It is precisely through such techniques that the films inform audiences that this was a genuine response to what happened to the man. This is authenticity. Let's take Ang Lee's Crouching Tiger, Hidden Dragon as another example. When Michelle Yeoh chases Zhang Ziyi and holds her down with her hands and legs, their moves become intertwined - one is attacking while the other is dodging. Yuan Heping, the choreographer, designed these moves to show audiences that this physical fighting is a real confrontation. This type of authenticity is exactly what we keep pursuing. In some films, people can fly through the air, but we cannot find any signs that they are genuinely flying. This being the case, we must create elaborate designs that persuade audiences to believe that these martial artists both really exist and are authentically chivalrous. Otherwise, audiences will think that what we have shown is fabricated. What a humiliation to martial arts!

Jia: You can compile your views on film into a book that possible also includes your personal experience.

Wu: Please allow me to make three more films. Actually, I am dreaming about them. I have told Yuan Heping that I will definitely make a costume drama. I want to shoot a war scene on horseback. However, no one is interested in this, so I just tried to shoot several scenes of fighting on horseback in my yet-to-be released film. I am waiting on the timing. When it comes, I will make these kinds of films. At the moment, I dare not pursue quick results and will take things slow so that the scenes of fighting on horseback will be more vivid and authentic. For example, I have never seen what it looks like when a horse is really shot, so how can I ensure authenticity when filming scenes where a horse gets shot? This is what I need to learn step by step.

Jia: Saifu and Mailisi have directed a lot of films with scenes of horses.

Wu: I have watched films with scenes of horses, but they are different from what I want to express. The director Mailisi once asked me to play the role of Genghis Khan. I refused because I do not look like a Mongolian at all. Let's return to martial arts films. If I am going to make an action film or a martial arts film, I return 
to the fundamentals, or, in other words, the initial purpose-what kinds of emotions is the film intending to express? I will first uncover the core of the story, then elaborately design the details of action moves, and then think about what types of unique things I want to show.

\section{Adhering to Original Aspirations and Being Square Inside but Round Outside}

Jia: How do you think the Chinese films should develop in the current historic context?

Wu: I was talking about this issue with some famous screenwriters several days ago. They complained about forcing themes on films. But then I asked them to consider their original intentions when they joined this industry. I said to them, if you're willing to, let's talk about values and if we can reach a consensus, then we can keep on talking. Like martial artists, literati also have their chivalry, and thus should pay more attention to writing scripts for martial arts films. Whether we are in an era of steel weapons, an era of firearms, or an era of information; whether we are living in poverty life or comfortable life; we are always in pursuit, always on the road, but there must be a process. In the current historic context, it is a good thing for the Chinese films to undergo some things-whether setbacks, premature ends, or the emergence of different voices. If things go too smoothly, then that might not be healthy. We invested about 1.3 billion yuan to produce the film The Battle at Lake Changiin. No matter how many problems we have encountered during the film shooting, I have always held a sincere hope that this film can stimulate the industrialization of Chinese films. It is not just about how many people can be trained or how professional things are. What really matters is that, no matter how many problems and setbacks we encounter, we learn lessons so that we can avoid these issues in the future. Just like with action films, it is necessary for martial arts films to undergo some setbacks. For instance, I want to change audiences' aesthetic ideas so as to make actors who are not particularly good-looking more charming to audiences. Where does their charm from? From their sincerity and kindness.

Jia: Have you found ways to achieve your goals?

Wu: I have been reading some books about film theory recently. Without doing so, how can I make myself seem convincing to the rest of the film industry? What can young people learn from me? I am committed to summarizing my experience into a set of film theories to make myself more convincing. I think shooting films is really about capturing the ways of the world. What a person says varies according 
to different contexts and times, even if they are speaking to the same person. Therefore, when shooting a film, we should focus on people's experiences of life and, emotions, and the ways of the world. It is only in this way, that we can put more genuine experience into films. In daily life, I always turn myself into an agreeable person, so I will not hurt people without being aware of it. Recently, I bought an ancient Chinese coin with a square hole inside and hung it in front of my bed to remind me to be a person who is "square inside and round outside." of course, the "round" here does not refer to being sly, but about not allowing my actions and words to unintentionally hurt others.

Jia: That's quite a way to be. As you have mentioned, traditional martial arts are different from modern ones and the older martial arts films are quite different from today's actions films.

Wu: Nowadays, young people account for a dominant part of the audiences and are at the helm of the future world. As a result, film styles will change according to the taste of audiences. If we continue to produce martial arts films the same as before, no one will want to watch them. Fortunately, young students have new ideas, even if they dare not speak them in front of academics. This being the case, martial arts films will not be produced solely in the ways they were in past. Now we have more appreciative audiences, more professional actors, and more advanced equipment, which means films of every genre will evolve in tune with improvements in the wider context.

Jia: Sure. I once wrote an article about James Cameron at a time when his films had still not been imported into China and people were unfamiliar with him. But gradually, his films gained recognition from Chinese audiences.

Wu: When it comes to James Cameron, we share some common points in how we sequence film narratives. He tends to develop his stories backwards, which I did in several parts of Wolf Warrior. It is only by carefully attempting various techniques, that you can make your story flexible, and open your mind to the best way for demonstrating what you want to express more clearly.

Jia: What are the features of main melody films produced by the current generation of directors and actors?

Wu: Since each era has its main themes, the films produced by filmmakers of each era are quite different. The new perspectives taken by the current generation producing films according to mainstream themes are quite inspiring to the film industry. These films are a bold experiment.

Jia: Today, many people, regardless of their age, have their dreams. Looking back, what were your original dreams? Do you still adhere to them now?

Wu: I don't know. I have no idea about your question. If anything, I wanted to play the hero Linghu Chong after I read The Smiling Proud Wanderer (Xiao'ao Jianghu written by Jin Yong) and wanted to play Yang Guo after reading The Return 
of the Condor Heroes (Shendiao Xialü written by Jin Yong). I was also inspired by watching the TV dramas Legend of the Condor Heroes (Shediao yingxiong zhuan, starring Felix Wong, 1983) and The Flying Fox of the Snowy Mountain (Xueshan feihu, starring Felix Wong, 1999). Since I was a child, I dreamed of being a great master. By the time I took a film role for the first time, I had changed my ideas about great masters. Then, what influenced me the most was martial arts, which taught me to demonstrate justice in a restrained way in films, rather than in an aggressive way.

Jia: Martial arts emphasize being restrained. Just as the old saying goes: laying down weapons is the essence of martial arts.

Wu: Most people may think the essence of martial arts is to attack, but I think once you become a martial artist, you have to show restraint, not injure anyone, and not bully the weak. To be honest, I'm not sure whether I still adhere to my original dreams or not.

\title{
Bionote
}

\author{
Leilei Jia \\ Chinese National Academy of Arts, Beijing, China \\ jialeilei1008@126.com
}

Leilei Jia is the former associate dean of the Chinese National Academy of Arts and serves as a researcher and doctoral supervisor. He is a doctor of theater, film and television literature and is among the 10th national educational inspectors of the Office of National Education Inspection. He also serves as the director of the Research Department of Chinese Film Schools of Beijing Film Academy, and the chief editor of the Journal of Film Studies published by Shanghai Film Academy of Shanghai University, and he is a member of the Film Censorship Commission of State Administration of Radio, Film, and Television. Leilei Jia was the associate director of Film and Television Research Institute, the dean of the Film and Television Department of the Graduate School, the director of the Research Center of Cultural Development Strategy, and the deputy dean of Chinese National Academy of Arts. He was the jury of Huabiao Film Awards and Golden Rooster Award. His publications include Film Linguistics (1996), The History of Chinese Martial Arts Films (2005), What Are Good Movies (2009), The Methodologies and Paradigms of Filmology (2015), and Cultural Industry and Cultural Soft Power (2016).

\section{Ruoting Zhang}

Communication University of China, Beijing, China

Ruoting Zhang is a postgraduate student at the School of International Studies of the Communication University of China. Her research interest is film and television dubbing and subtitling. Her translation of this article is supported by the China National Social Science Major Research Project "General History of Film Translation in China” (Grant number: 20\&ZD313). 